\title{
The evidence and feasibility of using pulse oximetry for the management of childhood pneumonia in low- and middle-income countries: a clinical review
}

\author{
Masahiro J. Morikawa ${ }^{1 *}$, Prakash R. Ganesh ${ }^{2}$
}

\begin{abstract}
${ }^{1}$ Department of Family Medicine, University of Virginia, Charlottesville, Virginia, United States of America
${ }^{2}$ Department of Family Medicine, Case Western Reserve University, Cleveland, Ohio, United States of America
\end{abstract}

Received: 14 November 2020

Revised: 29 December 2020

Accepted: 05 January 2021

\section{*Correspondence:}

Dr. Masahiro J. Morikawa,

E-mail:mjmkobe@gmail.com

Copyright: ( $)$ the author(s), publisher and licensee Medip Academy. This is an open-access article distributed under the terms of the Creative Commons Attribution Non-Commercial License, which permits unrestricted non-commercial use, distribution, and reproduction in any medium, provided the original work is properly cited.

\begin{abstract}
The use of pulse oximetry (POx) for the diagnosis and management of childhood pneumonia has been of interest in recent years. In order to effectively employ POx to manage childhood pneumonia in LMICs, we aim to answer the following five questions through a literature review. These five questions are: 1) Which clinical signs are reliable to detect hypoxia? 2) What is the prevalence of hypoxia among those diagnosed with pneumonia? 3) Does the detection of hypoxia among clinical pneumonia patients improve survival? 4) How reliable are current POx devices in the field? and 5) What are the problems in introducing POx in the field?

We searched three keywords-IMCI, childhood pneumonia and pulse oximetry, with the PubMed search engine and extracted 119 articles and book chapters. Each article was reviewed to answer above five questions. The literature review indicates that none of the clinical signs reliably detect hypoxia in children. The prevalence of hypoxia among pneumonia varied based on the study. $17-32 \%$ of patients without a diagnosis of pneumonia presented with hypoxia. There are currently no randomized trials available to demonstrate the benefit of pulse oximetry in childhood pneumonia survival. Various devices and probes are used in different studies and there are still technical and logistical issues related to POx device use in the field to manage childhood pneumonia in LMICs. There are numerous barriers to train healthcare workers in all levels. We need affordable, reliable, easy to use pulse oximetry for childhood pneumonia management.
\end{abstract}

Keywords: Childhood pneumonia, Global health, Pulse oximetry

\section{INTRODUCTION}

Childhood pneumonia is the leading cause of death under age the age of five and has killed more than 800,000 children in 2017 worldwide. $^{1}$ It accounts for $19 \%$ of all under 5-years mortality and the majority of them are in low-and middle-income countries (LMICs), especially in Sub-Saharan Africa and South East Asia. ${ }^{2}$ Worldwide, $81 \%$ of pneumonia deaths is in the first two years of life. ${ }^{3}$
The integrated management of childhood illnesses (IMCI) approach is a set of clinical guidelines based on simple clinical signs that was developed for healthcare providers to diagnose and treat common pediatric conditions including childhood pneumonia in resource poor settings. The IMCI approach was introduced in 1995 by UNICEF and the WHO and evolved through a series of field verification studies. $^{4-6}$ 
There have been several revisions to the IMCI guidelines for the use of clinical signs since the early phases of its implementation. IMCI clinical signs for pneumonia suffered from low specificity and tended to over-refer. ${ }^{7}$ In one study, only $55 \%$ of children who would have been referred by the algorithm actually required hospital admission and the over-referral was due to the low specificity of chest indrawing in those with pneumonia. Since then, there have been ongoing discussions regarding which clinical signs should be incorporated into the algorithm. However, recent studies have shown that none of the clinical signs are reliable in making the diagnosis of pneumonia. ${ }^{8}$ Therefore, there is a need to search for another reliable, easy-to-use modality to detect childhood pneumonia in LMICs. Meanwhile, pulse oximetry (POx) has been employed in high-income countries routinely to detect hypoxia, which is a common finding in severe pneumonia. In fact, in the pediatric primary care clinic study in North America they found that POx use has increased to $85 \%$ of the practice. ${ }^{9}$ There is an increasing interest among the global health community to employ $\mathrm{POx}$ in the management of childhood pneumonia. In expert consensus report by WHO in 2018, experts agreed on the use of POx if available. $^{10}$ However, applicability, availability, scalability of POx for the management of childhood pneumonia has not been clearly examined.

\section{DESIGN}

We examined the feasibility and problems with introducing POx for managing childhood pneumonia in LMICs by reviewing the current literature to answer the following five clinical questions. These are 1) Which clinical sign are reliable to detect hypoxia? 2) What is the prevalence of hypoxia in those presenting with pneumonia? 3) Does the detection of hypoxia among clinical pneumonia patients improve survival? 4) How reliable are current POx devices in the field? And 5) What are the challenges in introducing POx in the field?

We conducted the following literature search on PubMed on August $17^{\text {th }}, 2020$ with the following keywords: childhood pneumonia, IMCI, and pulse oximetry. The combination of these 3 words extracted 119 articles and book chapters. The combination of childhood pneumonia and IMCI extracted 101 articles, childhood pneumonia and POx extracted 36 articles, IMCI and POx extracted 5 articles, all three words extracted 5 articles including some duplicates). Both authors went through all the articles to examine the relevance to answer the above five questions.

\section{FINDINGS}

One of the ongoing arguments regarding the IMCI approach for childhood pneumonia is the case definition. Fever accompanied with cough and/or shortness of breath is the standard definition. However, in endemic areas, up to $30 \%$ of febrile patients can have malaria and a pneumonia co-infection. ${ }^{11}$ Van den Bruel addressed that shortness of breath is commonly present in pneumonia patients. ${ }^{12}$ In addition, Lozano has pointed out that hypoxia is a more reliable marker for pneumonia. ${ }^{13}$ There was an evidence that tachypnea correlates more with hypoxia among other clinical signs. ${ }^{14} \mathrm{POx}<92 \%$ was the strongest predictor for pneumonia and it was correlated with an increased risk of death due to pneumonia. ${ }^{15,16}$

Among the clinical signs of pneumonia, chest indrawing was studied in number of previous studies; Kahigwa showed chest indrawing is a reliable clinical sign with good inter-observer agreement and the young infants clinical signs study (YICS) identified seven clinical signs for severe illness of pneumonia, one of which was severe chest indrawing. ${ }^{17,18}$ However, recent studies have demonstrated that none of the clinical signs are specific for diagnosing childhood pneumonia and Alwadhi found that no single clinical sign can perform as well as POx to predict hypoxia in childhood pneumonia. ${ }^{19,20}$

The prevalence of hypoxia measured by POx varies among the studies we examined in our review. An earlier study showed a median reading for severe pneumonia of $70 \%$, while in the respire study, definitive pneumonia patients had POx readings of $80 \%$ while no infection was seen at readings of $92 \% .^{21,22}$ One study showed that POx $<90 \%$ was a predictor for treatment failure in pneumonia. ${ }^{23}$ POx could correctly identify $20-30 \%$ more pneumonia patients with hypoxia than clinical signs alone. $^{24}$

Duke studied a population in Papua New Guinea and demonstrated that the introduction of POx and oxygen decreased mortality by $35 \% .^{25,26}$ Floyd employed modeling techniques to estimate that the impact of POx for childhood pneumonia would be \$2.97-52.92/DALY averted. ${ }^{27}$ Nonetheless, there are no randomized clinical trials to demonstrate the benefit of employing POx for survival in childhood pneumonia.

Despite increasing supportive evidence for the usefulness of POx in LMICs, current guidelines recommend the use only when the technology is available. ${ }^{28} \mathrm{We}$ tried to delineate whether there was a reliable, reusable, and affordable POx device in the field and found a number of technical and design problems related to the devices seen in previous studies: Hamid pointed out that the attachment of the probe to the fingers of small children is often difficult and the durability of probes in the field is also questionable. ${ }^{29}$ Weber found that finger clip on sensors lasted on average six months. ${ }^{30}$ The cost of POx devices is another concern-reusable sensors cost $\$ 150$ 200 and are good for approximately 12 months while the device itself can cost $\$ 100-1000$ per device. ${ }^{31}$ Clip-on probes in one study cost $\$ 25$ and the device itself was $\$ 250 .^{32}$ Lastly, the time to obtain stable readings, which is known as lead time, is another concern that is often raised in the field. It was unclear how much time they waited to obtain stable readings in the field, but in one study, the 
median time was 219-228 seconds. ${ }^{33}$ McCollum argued based on their study in Malawi, the ideal lead time should be less than 30 second. ${ }^{32}$

There are several Apps developed to help healthcare providers manage childhood pneumonia that incorporate POx readings into the App. The mPneumonia App was developed in 2015 and POx is incorporated into the App. $^{34,35}$ The ALMANACH App was developed in Tanzania and POx was incorporated as well. ${ }^{36,37}$ But the outcome of employing these two Apps is not available at this moment. There are only few studies disclosing the time from application of the probe until they get stable readings of $\mathrm{POx}$ on patients.

There are several studies that discuss the problems of implementing POx in the field. Nab wire found that the majority of district hospital personnel didn't know how to use POx $(76 \%){ }^{38}$ Ginsburg systemically surveyed and identified several barriers to implement POx. ${ }^{39}$ Another study in Cambodia demonstrated low availability and poor knowledge in usage of Pox in district hospitals and health centers. ${ }^{40}$ Usability focus group discussions were conducted in one study in four countries, Cambodia, Ethiopia, South Sudan and Uganda and showed high interest for the device but the actual usage is low. ${ }^{41}$

\section{DISCUSSION}

We conducted this review to verify the scientific evidence and readiness to incorporate $\mathrm{POx}$ for the management of childhood pneumonia in LMICs. The literature does confirm that there is no strong evidence to support the use of relying only on clinical signs to diagnose childhood pneumonia among experts. Despite the wide usage of POx as a routine tool to assist in the diagnosis of pneumonia in high income countries, we found the prevalence of hypoxia among clinical pneumonia in LMICs varied widely. In addition, we found that there have been no randomized clinical trials to verify that POx usage changes the outcomes of pneumonia except for an ecological study to compare the before and after introduction of $\mathrm{POx}$ and supplementary oxygen. ${ }^{25}$ Currently, there are no standard design or devices of pulse oximeters widely accepted in LMICs for childhood pneumonia. There are still several technical and logistical issues that have to be solved to make the device worthwhile in the field.

First, the probe design. In high income countries, disposable adhesive tape is used to wrap the probe around the digits of children to obtain accurate POx readings. Disposable tape is not practical in resource-poor settings due to the cost and lack of supply. The popular and affordable POx device uses a clip mechanism with two rigid plastic plates and two sensors to pincer finger/toe to the probe, but the challenge for this model is 1) the hinge can easily break after repetitive use 2) it is hard to fit a rigid clip onto the tiny digits of newborns and infants to obtain stable readings and 3) sick children are often malnourished and have even smaller digits compared with those of children in high income countries. Nonetheless, previous studies have been conducted to use several different types of existing probes from high income countries. The second issue is the lead time, the time from application of the probe until we get stable readings from the device. Third is the cost of the device. The available devices can cost \$250-300 for the oximeter itself. In addition, you have to purchase appropriately sized probes to go with the oximeter to obtain accurate POx readings. There was a wide variation in price and lead time until stable readings were obtained from patients.

Therefore, the device that is needed in the field now has to be reliable enough to obtain accurate and stable readings within 30 seconds from application of the device, can handle high throughput and be affordable in LMICs.

Then, finally, there is the issue of training. Previous studies demonstrated that the current knowledge and usage of POx in the field is not optimal, despite the fact POx and the oxygen training manual by the WHO has been around for nearly 10 years. ${ }^{42}$ We have to develop a novel way to train frontline health workers to effectively use POx to manage childhood pneumonia. The device alone will not help patients. It should go with a welltrained hand to make the technology effectively work to save lives.

\section{CONCLUSION}

Based on our clinical review to address these five clinical questions in the application of pulse oximetry in the management of childhood pneumonia, we found that there are considerable variations in terms of the prevalence of hypoxia among studies and there is no clear demonstration of the effectiveness of the probes used in the studies. The efficacy of the use of pulse oximetry in childhood pneumonia management should be examined with prospective studies with more reliable and affordable probes that would prove effective in practice.

Funding: No funding sources

Conflict of interest: None declared

Ethical approval: Not required

\section{REFERENCES}

1. WHO Fact Sheets: Pneumonia. Available from: https://www.who.int/news-room/factsheets/detail/pneumonia. Accessed Oct 17, 2020.

2. Rudan I, Boschi-Pinto C, Biloglav Z, Mulholland K, Campbell H. Epidemiology and etiology of childhood pneumonia. Bull WHO. 2008;86:408-16.

3. Walker C, Rudan I, Liu L, Nair H, Theodoratou E, Bhutta $\mathrm{Z}$ et al. Childhood pneumonia and diarrhoea 1. Global burden of childhood pneumonia and diarrhoea. Lancet. 2013;381:1405-16. 
4. Gove S. Integrated management of childhood illness by outpatient health workers: technical basis and overview. Bull WHO. 1997;75(1):7-24.

5. Weber M, Mulholland E, Jaffar S, Troedsson H, Gove S, Greenwood B. Evaluation of an algorithm for the integrated management of childhood illness in an area with seasonal malaria in the Gambia. Bull WHO. 1996;75(1):25-32.

6. Simoes E, Desta T, Tessema T, Gerbresellassie T, Dagnew M, Gove S. Performance of health workers after training in integrated management of childhood illness in Gondar, Ethiopia. Bull WHO. 1997;75(1):43-53.

7. Kalter H, Schillinger J, Hossain M, Burnham G, Saha $\mathrm{S}$, De Wit $\mathrm{V}$ et al. Identifying sick children requiring referral to hospital in Bangladesh. Bull WHO. 1997;75(1):65-75.

8. Rambaud-Althaus C, Althaus F, Genton B, D'Acremont V. Clinical features for diagnosis of pneumonia in childrne younger than 5 years: a systematic review and meta-analysis. Lancet Infect Dis. 2015;15:439-50.

9. Ambroggio L, Mangeot C, Kurowski E, Graham C, Korn P, Strasser M et al. Guideline adoption for community-acquired pneumonia in the outpatient setting. Pediatrics. 2018;142(4):e2018-331.

10. WHO. Exploratory meeting to review new evidence for Integrated Management of Childhood Illnedd danger signs, Geneva, Switzerland, 4-5 September 2018. Geneva, Switzerland. 2019.

11. Ukwaja K, Aina O, Talabi A. Clinical overlap between malaria and pneumonia: can malaria rapid diagnostic test play a role? J Infect Dev Ctries. 2011;5(3):199-203.

12. Van den Bruel A, Haj-Hassan T, Thompson M, Buntinx F, Mant D. Diagnostic value of clinical features at presentation to identify serious infection in children in developed countries: a systematic review. Lancet. 2010;375:834-45.

13. Lozano J, Steinhoff M, Ruiz J, Mesa M, Martinez N, Dussan B. Clinical predictors of acute radiological pneumonia and hypxaemia at high altitude. Arch Dis Childhood. 1994;71:323-7.

14. Crocker M, Hossen S, Goodman D, Simkovich S, Kirby M, Thompson L et al. Effects of high altitude on respiratory rate and oxygen saturation reference values in healthy infants and children younger than 2 years in four countries: a cross-sectional study. Lancet Glob Health. 2020;8:e362-73.

15. Newman M, Monuteaux M, Scully K, Bachur R. Prediction of pneumonia in a pediatric emergency department. Pediatrics. 2011;128:246-53.

16. Lazzerini M, Sonego M, Pellegrin M. Hypoxemia as a mortality risk factor in acute lower respiratory infections in chidlren in low and middle-income countries: Systematic review and meta-analysis. Plos One. 2015;10(9):e0136166.

17. Kahigwa E, Schellenberg D, Schellenberg J, Aponte $\mathrm{J}$, Alonso P, Menendez C. Inter-observer variation in the assessment of clinical signs in sick Tanzanian children. Trans R Soc Trop Med Hyg. 2002;96:162-6.

18. The Young Infants Clinical Signs Study Group. Clinical signs that predict severe illness in chidlren under age 2 months: a multicenter study. Lancet. 2008;371:135-42.

19. Rambaud-Althaus C, Althaus F, Genton B, D'Acremont V. Clinical features for diagnosis of pneumonia in childrne younger than 5 years: a systematic review and meta-analysis. Lancet Infect Dis. 2015;15:439-50.

20. Alwadhi V, Dewan P, Malhotra R, Shah D, Gupta P. Tachypnea and other danger signs vs pluse oximetry for prediction of hypoxia in severe pneumonia/very severe disease. Indian Pediatrics. 2017;54:729-34.

21. Duke T, Mgone J, Frank D. Hypoxaemia in children with severe pneumonia in Papua New Guinea. Int $\mathbf{J}$ Tuberc Lung Dis. 2001;5(6):511-9.

22. Bruce N, Weber M, Arana B, diaz A, Jenny A, Thompson $\mathrm{L}$ et al. Pneumonia case-finding in the RESPIRE Guatemala indoor air pollution trial: standardizing methods for resource-poor settings. Bull WHO. 2007;85:535-44.

23. King C, McCollum E, Mankhambo L, Colbourn T, Beard J, Burgess D et al. Can we predict oral antibiotic treatment failure in children with fastbreathing pneumonia managed at the community level? A prospective cohort study in Malawi. Plos One. 2015.

24. Duke T, Subhi R, Peel D, Fery B. Pulse oximetry: Technology to reduced chidl mortality in developing countries. Ann Trop Pediatr. 2009;29:165-75.

25. Duke T, Wandi F, Jonathan M, Matai S, Kaupa M, Saavu $M$ et al. Improved oxygen systems for childhood pneumonia: a multihospital effectiveness study in Papua New Guinea. Lancet. 2008;372:1328-33.

26. Bhutta Z, Das J, Rizvi A, Gaffey M, Walker N, Horton $S$ et al. Maternal and child nutrition 2. Evidence-based interventions for improvement of maternal and child nutrition: what can be done and at what cost? Ibid. 2013;382:452-77.

27. Floyd J, Wu L, Burgess D, Izadnegahdar R, Mukanga D, Ghani A. Evaluating the impact of pulse oximetry on childhood pneumonia mortality in resource-poor settings. Nature. 2015;528:s53-9.

28. McCollum E, Ginsburg A. Outpatient managment of children with World Health Organization chest indrawing pneumonia: implementaion risks and propsed solutions. Clin Inf Dis. 2017;65(9):1560-64.

29. Hamid M, Chandna A, Siddiqui S, Fayyaz J. Pulse oxymetry: a reliable and cost effective screening tool in children with pneumonia for developing countries. J Pak Med Assoc. 2016;66(8):1015-8.

30. Weber W, Mulholland E. Pulse oxymetry in developing countries. Lancet. 1998;351:1589.

31. Duke T, Graham S, Cherian M, Ginsburg A, English $\mathrm{M}$, Howie $\mathrm{S}$ et al. Oxygen is an essential medicine: a call for internaitonal action. Int $\mathrm{J}$ Tuberc Lung Dis. 2011;14(11):1362-8. 
32. McCollum E, King C, Deula R, Zadutsa B, Mankhambo L, Nambiar B, et al. Pulse oximetry for children with pneumonia treated as outpatients in rural Malawi. Bull WHO. 2016;94:893-902.

33. Hudson J, Nguku S, Sleiman J, Karlen W, Dumont $\mathrm{G}$, Petersen $\mathrm{C}$ et al. Usability testing of a prototype phone oximeter with healthcare providers in highand low-medical resource environments. Anaesthesia. 2012;67:957-67.

34. Ginsburg A, Delarosa J, Brunette W, Levari S, Sundt M, Larson C et al. mPneumonia: Development of an innovative mHealth application for diagnosing and treating childhood pneumonia and other childhood illnesses lin low-resource settings. PloS One. 2015.

35. Ginsburg A, Agyemang C, Ambler G, Delarosa J, Brunette W, Levari S, et al. mPneumonia, an innovation for diagnosing and treating childhood pneumonia in low-resource settings: A feasibility, usabilyt and acceptability sutyd in Ghana. Plos One. 2016;11(10):e0165201.

36. Keitel K, Kagoro F, Samaka J, Masimba J, Said Z, Tamba $\mathrm{H}$ et al. A novel electronic algorithm using host biomarker point-of-care tests for the management of febrile illnesses in Tanzanian chidlren (e-POCT): a randomized, controlled noninferiority trial. Plos Medicine. 2017;14(10):e1002411.

37. Shao A, Rambaud-Althaus C, Samaka J, Faustine A, Perri-Moore S, Swai N, et al. New algorithm for managing childhood illness using mobile technology (ALMANACH): A controlled non-inferiotiy study on clinical outcome and antibiotic use in Tanzania. Plos One. 2015;10(7):e0132316.

38. Nabwire J, Namasopo S, Hawkes M. Oxygen availability and nursing capacity for oxygen therapy in Ugandan pediatric wards. J Trop Pediatr. 2018;64:97-103.

39. Ginsburg A, Van Cleve W, Thompson M, English M. Oxygen and pulse oxymetry in childhood pneumonia: a survey of healthcare providers in resource-limited settings. J $\quad$ Trop Pediatr.2012;58:389-93.

40. Ginsburg A, Gerth-Guyette E, Mollis B, Gardner M, Chham S. Oxygen and pulse oxymetry in childhood pneumonia: surveys of clinicians and student clinicians in Cambodia. Trop Med and Int Health. 2014;19(5):537-44.

41. Spence H, Baker K, Wharton-Smith A, Mucunguzi A, Matata L, Habte T et al. Chlidhood pneumonia diagnostics: communith health workers' and national stakeholders' differeing perspectives of new and existing aids. Global Health Action. 2017;10:1290340.

42. WHO "The WHO Pulse Oximetry Training Manual" Geneva, Switzerland; 2011.

Cite this article as: Morikawa MJ, Ganesh PR. The evidence and feasibility of using pulse oximetry for the management of childhood pneumonia in low- and middle-income countries: a clinical review. Int J Community Med Public Health 2021;8:993-7. 